\title{
Optics workshops designed to preschool children (age 3 to 6 years)
}

Charvel Lopez, Cristina Solano

Charvel Lopez, Cristina Solano, "Optics workshops designed to preschool children (age 3 to 6 years)," Proc. SPIE 9946, Optics Education and Outreach IV, 994617 (27 September 2016); doi: 10.1117/12.2238755

SPIE Event: SPIE Optical Engineering + Applications, 2016, San Diego, California, United States 


\title{
Optics workshops designed to preschool children (age 3 to 6 years)
}

\author{
Charvel Lopez and Cristina Solano \\ divulgacion@cio.mx
}

Outreach Coordination, Centro de Investigaciones en Optica, A. C, León, Gto, México

\begin{abstract}
Since 2005, it was decided in Mexico that children have to start their formal education at the age of 3 years, two years earlier that in many other countries. This change was done to increase activities that enhance the social interaction and stimulus (knowledge and skills) of the students to prepare them to the next academic level. The main drawback of the developed curriculum for the younger children is that it does not include enough scientific activities. The work presented here is the answer of a particular initiative of some teachers to implement scientific workshops in optics. We have found that preschoolers are attracted to scientific activities if the material is presented in the right way. While design any scientific activity it is important to remember that young children want to know about their world without changing it, they have to experience the principle without memorizing, therefore the language used to describe concepts, ideas or terms has to be carefully chosen to avoid confuse preschoolers that can lose track of the activity. The scientific information has to be very clear and limited to a single physical principle and the concepts have to be presented in a way to include games as a learning activity that allow them to experience with the results.
\end{abstract}

\section{Keywords: Outreach activities, Preeschool children; Education}

\section{Introduction}

In 2005 it was officially published an amendment to the education for the Preschool curricula with the aim to integrate and facilitate continuity with the of primary curriculum, developing, above all, a number of competencies (skills and attitudes) regarding self-esteem, coexistence, social interaction, respect for others and the development of knowledge. These set of skills and attitudes will allow the preschooler to function fully and effectively in everyday life.

These changes have to be in line with the recent policy with the aim to increase the awareness in technological advance in the general population what it has been called the "Knowledge Socitey." Therefore, the integration of science in their educational spaces it is essential to ensure a future where knowledge and scientific method are part of the intellectual process.

\section{Developed Work}

Preschool children are an important part of the population because with them it is possible to develop science interest for all their lives. These activities have to be done although there is not an official program for young children.

The work presented here is the answer of a particular initiative of some teachers to include scientific activities as an essential step to ensure a future where knowledge and scientific method are part of their intellectual process. We have found that preschoolers are attracted to scientific activities if the material is presented in the right way. Therefore it is necessary as that these outreach activities have a series of actions to complement a multi - disciplinary and multi- sensory experience as the child must grasp the science empirically because of their urgent need to engage sensory with the environment .

Optics Education and Outreach IV, edited by G. Groot Gregory, Proc. of SPIE Vol. 9946, 994617

(C) 2016 SPIE · CCC code: $0277-786 X / 16 / \$ 18 \cdot$ doi: $10.1117 / 12.2238755$ 


\section{Suggested concepts}

The most important thing to remember, when is working to children, is to enhance their creative and curiosity, necessary to work in science.

1- Atend small groups: This will achieve an immediate and personal support to answer their questions and hear their comments. It contributes to a better management of the group.
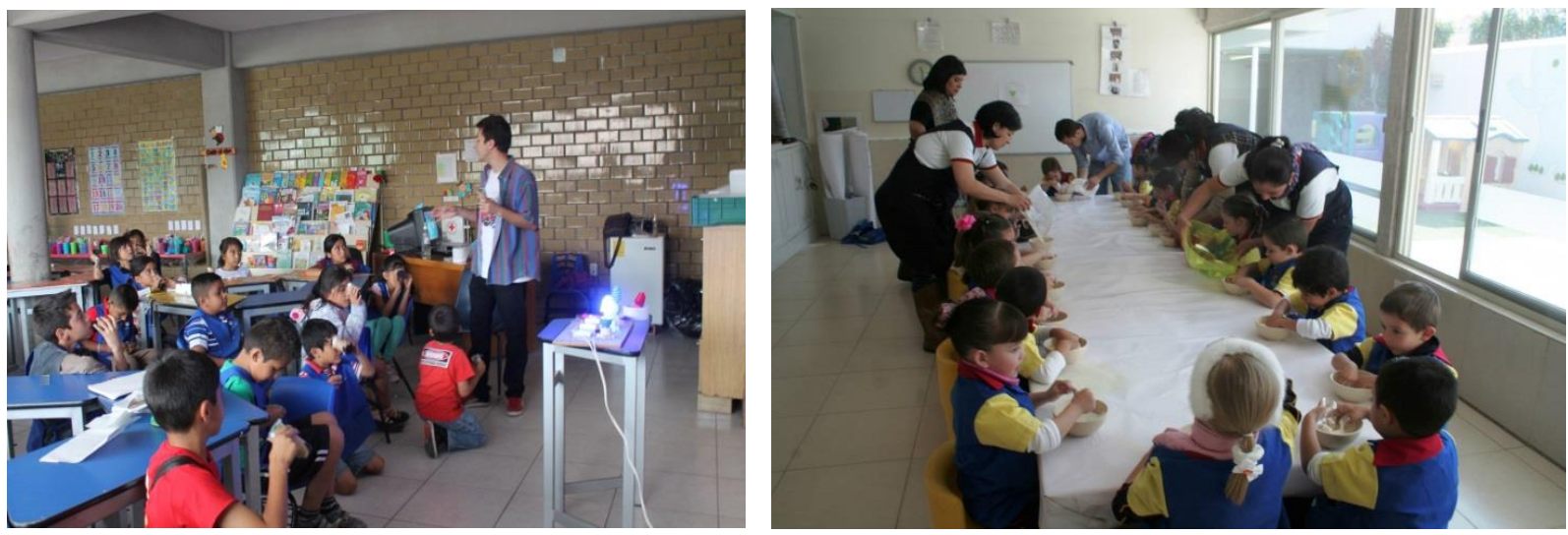

2- Use the game as a learning tool: Children ages 3 to 7 are governed by the game. The game allows them to know rules and procedures. Scientific workshops should include a dynamic game with the intention of systematizing the process performed in the activity. For each scheduled workshop a dynamic game -oriented scientific concepts that want to present should be considered.
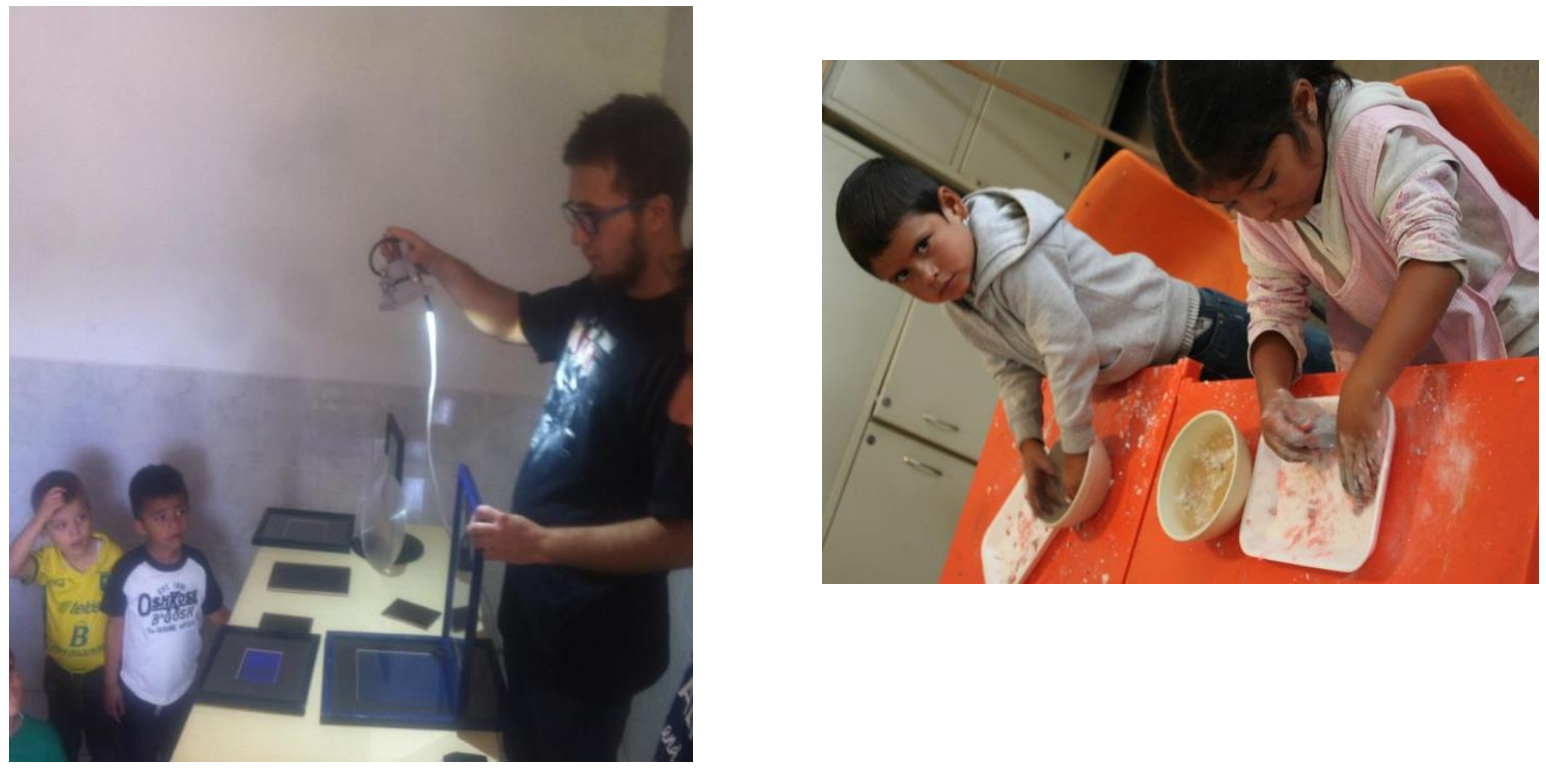
3- Learning: "How does the world function?" The adults know (or believe to know) the world and want to change it. Young children just want to understand it. Use simple language as the children may be confused and lose track of the activity.

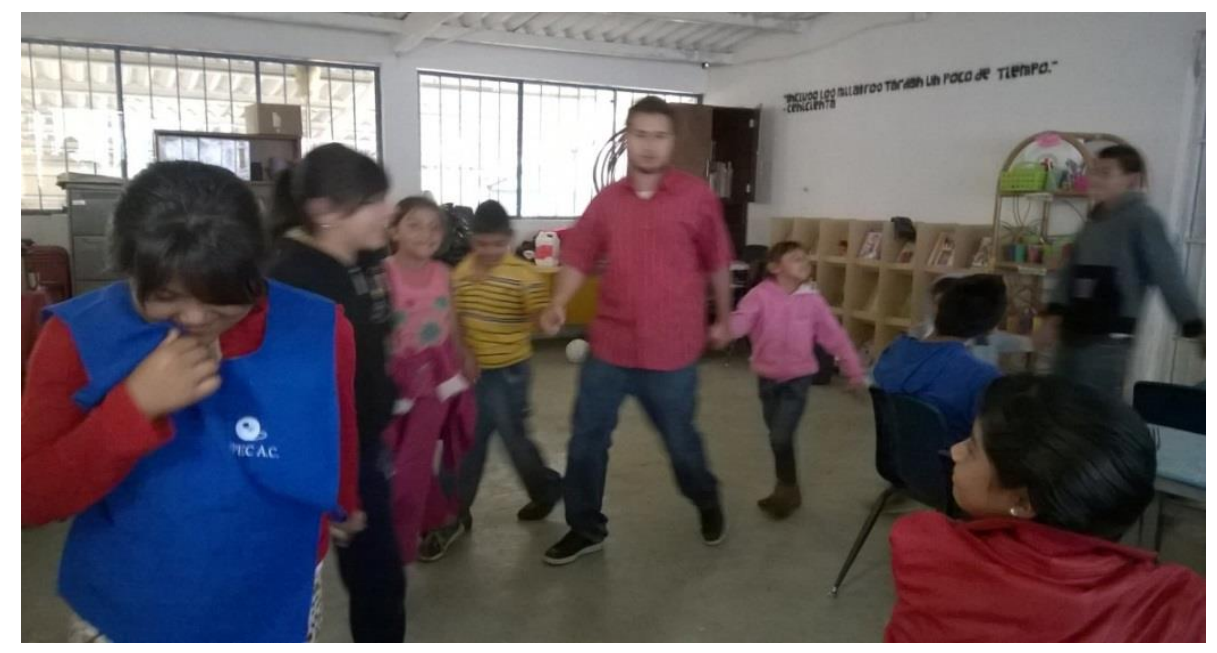

4- Use examples seen in their everyday environment to connect science with moments of their normal life: Emphasize the observation of everyday phenomena bringing them to understand the role of science as a daily tool. Connecting scientific knowledge with their everyday environment helps to expand science outside of the formal education spaces.

5-Experimenting the phenomenon: Do not worry if the children cannot learn or memorize a concept, the experience is more important. They must understand the world through a proprietary process of testing and experimentation. The use of short ideas can be complemented with additional material (experiment, video, interaction with an object, etc.)
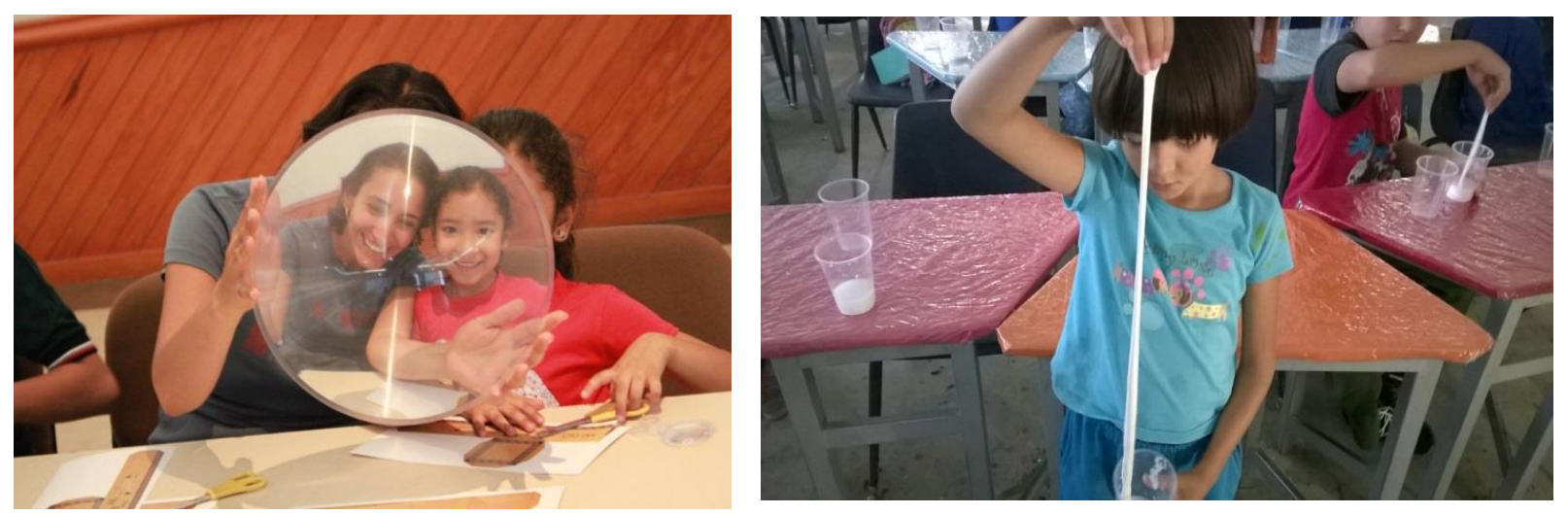

6- Starting with a short story can help to introduce them to the subject because their vivid imagination. The narrative helps to reinforce a scientific issue from another discipline.

7- Design outdoor activities: Consider the use of open space with adequate furniture for scientific activities. Children feel more relaxed in this kind of environment. 


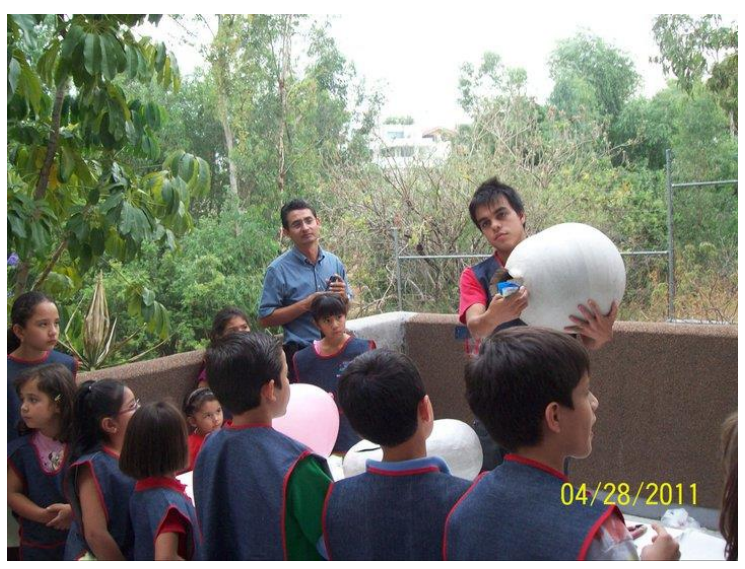

8- Always listen their comments they made regarding what was presented: Preschool children have the need to share different experiences that surprises them too much and therefore it is important to listen and provide feedback to focus them on the appropriate topic. Because of their various comments is necessary to guide their views directly to a successful response seeking to maintain a conversation where appropriate conclusions for understanding are provided.

9- Design specific projects for preschoolers: Ask a concise question based on their regular environment. What the child knows? Example: Theme: "The Rainbow," with the intention of experiencing the refraction of light

Conduct short questions using keywords regarding the activity that is being presented.

1 - I see

2- I can find in

3- It is used to

4 - I do it with

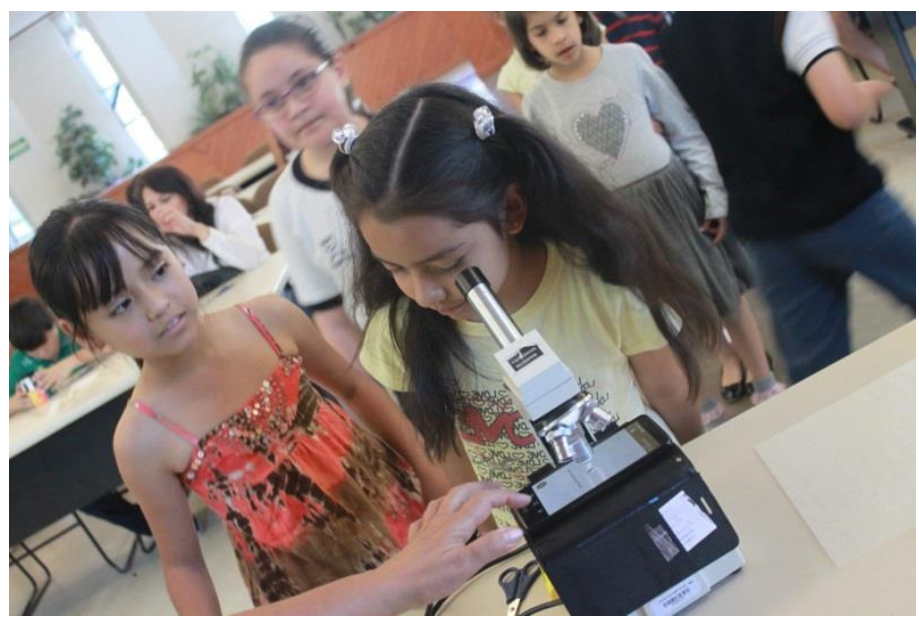

10- As an extra activity to reinforce their approach to science and the scientific environment preschoolers should visit a laboratory to know where scientists work (this activity can be possible when they visit a research center). This activity will expand their scientific expertise. Visiting different spaces at a young age stimulates their imagination. If this activity is not possible a science museum or a factory will have a similar effect. 


\section{Conclusions}

By carrying out such measures the cognitive spectrum and understanding of young children can be reached. Scientific disclosure made under these measures present in them a stimulation of the right skills according with their age: restlessness and utter shock to experiment and experience the world around them focused on achieving educational consequences basic processes of the scientific method.

By presenting science as a set of process, not only as scientific concepts through various elements: experimental, playful, literary -narrative and managing to make an interconnection with the environment around it was observed a focused interest in the subject concise that I wanted to present and check.

They also showed over- stimulation around all the materials involved, wanting to apply some changes by themselves demanding to check their properties and then achieving connections with their own environment to raise questions of concern.

At the end of the activity they formulated a number of observations with the following approaches:

$-¿$ Can the process be modified by adding some other ingredient?

-They related similar events in their family arguing that there possibly seen the phenomenon analyzed in the activity.

Bringing science to their everyday spaces of development, whether routine or leisure, forces them to create intimate ties of his life making them to assimilate scientific concepts science as their own to understand the world. 